\title{
Efficacy of a newly modified technique for distal limited open stenting in octogenarians with aortic arch aneurysm
}

\author{
Mitsumasa Hata, MD, PhD, Yukihiko Orime, MD, Shinji Wakui, MD, Tetsuya Nakamura, MD, \\ Rei Hinoura, MD, Atsushi Harada, MD, and Kenji Akiyama, MD, PhD
}

\begin{abstract}
Objective: We assessed the efficacy of distal limited open stenting procedure in octogenarians with distal aortic arch aneurysm.

Methods: During the last 5 years, 24 patients underwent distal limited open stenting. Mean patient age was $81.6 \pm 2.5$ years, ranging from 80 to 90 years. The hemicircumference of the anterior surface of the arch around the left common carotid artery was obliquely incised, and a J-Graft Open Stent (Japan Lifeline Co, Ltd, Tokyo, Japan) was inserted into the descending aorta. During open stenting, circulatory arrest was induced at a rectal temperature of $28^{\circ} \mathrm{C}$ without any cerebral perfusion. As soon as the proximal side of the stent graft and aortic incision were concomitantly sutured, rapid rewarming was initiated through heated blood perfusion.
\end{abstract}

Results: The durations of circulatory arrest, aortic crossclamping, cardiopulmonary bypass, the overall operation, postoperative mechanical ventilation, and hospital stay were 17.0 minutes, 27.8 minutes, 106.1 minutes, 167.6 minutes, 11.0 hours, and 13.9 days, respectively. The in-hospital mortality was $0 \%$. There were no incidences of brain damage, renal failure, or respiratory failure. At the time of this study, 21 patients were doing well and visiting the outpatient clinic, and 19 scored more than 20 points on the Mini-Mental State Examination, indicating no development of dementia. The actuarial survival at 5 years was $82.4 \%$.

Conclusions: This unique technique is safe and effective. It is a very attractive procedure that can contribute to maintaining a good long-term quality of life for octogenarians with distal aortic arch aneurysm. (J Thorac Cardiovasc Surg 2017;153:530-5)

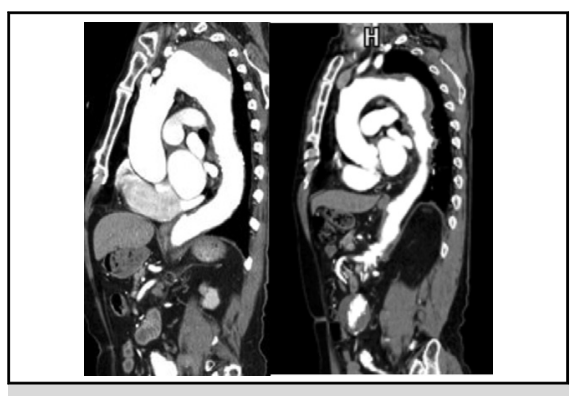

Shaggy aorta is associated with neurologic complications during TEVAR.

\section{Central Message}

Our newly developed technique of distal limited open stenting is an attractive procedure for treating distal aortic arch aneurysms in octogenarians.

\section{Perspective}

Our newly developed technique of distal limited open stenting for distal aortic arch aneurysm has resulted in a positive trend toward more favorable outcomes in octogenarians. It was superior for avoiding neurologic complications.

See Editorial Commentary page 536.
In the recent aging society, the number of octogenarians with cerebrovascular or respiratory disorders undergoing thoracic endovascular aortic repair (TEVAR) for distal aortic arch aneurysm (DAAA) has been steadily increasing. Although elderly patients with DAAA may survive because of less-invasive catheter techniques, the large aneurysm around the distal arch to the descending aorta often, particularly in octogenarians, has mural thrombi and

From the Department of Cardiovascular Surgery, Nihon University Hospital, Tokyo, Japan.

Received for publication May 27, 2016; revisions received Sept 2, 2016; accepted for publication Sept 16, 2016; available ahead of print Oct 20, 2016.

Address for reprints: Mitsumasa Hata, MD, PhD, Department of Cardiovascular Surgery, Nihon University Hospital, 1-6 Kanda, Surugadai, Chiyoda-ku, Tokyo 101-8309, Japan (E-mail: hata.mitsumasa@nihon-u.ac.jp).

$0022-5223 / \$ 36.00$

Copyright (c) 2016 by The American Association for Thoracic Surgery

http://dx.doi.org/10.1016/j.jtcvs.2016.09.049 atherosclerotic plaques-shaggy aorta—a condition associated with a high incidence of neurologic complications during TEVAR. ${ }^{1}$ We have established a new, lessinvasive, and quick procedure, distal limited open stenting, to prevent complications associated with deep hypothermia, a longer duration of cerebral protection, and a longer duration of cardiopulmonary bypass $(\mathrm{CPB}) .^{2}$ The aim of this study was to assess the efficacy of our unique procedure in octogenarians undergoing open surgery for DAAA.

Scanning this QR code will take you to a video for the article. 


\section{Abbreviations and Acronyms \\ TEVAR $=$ thoracic endovascular aortic repair \\ DAAA $=$ distal aortic arch aneurysm \\ $\mathrm{CPB}=$ cardiopulmonary bypass \\ MMSE $=$ Mini-Mental State Examination}

\section{MATERIALS AND METHODS}

Between January 2011 and April 2016, a total of 27 octogenarians with DAAA were referred to our hospital. Of these, 3 patients did not undergo surgical treatment because they already had a diagnosis of Alzheimer-type senile dementia and were bedridden at a care institution. Therefore 24 consecutive octogenarian patients were reviewed. Individual consent for this study was obtained from all patients, and institutional review board approval was obtained before publication of this article and reporting of the information. Five patients $(20.8 \%)$ were women, and the patients' average age was $81.6 \pm 2.5$ years, ranging from 80 to 90 years. The average maximum diameter of the DAAA was $60.6 \pm 5.5 \mathrm{~mm}$. Among the patients, $3(12.5 \%)$ had coronary artery disease, $8(33.3 \%)$ had a respiratory disorder, $5(20.8 \%)$ had atrial fibrillation, and $3(12.5 \%)$ had an old cerebral infarction. Contrast computed tomographic examinations showed a large DAAA with mural thrombi and atherosclerotic plaques in all patients, so they were considered to be at risk for stroke during the TEVAR approach. If the aneurysm is located more on the proximal side of the left common carotid artery, the use of this technique is not indicated, and the total arch replacement must be performed under moderate hypothermic arrest with antegrade selective cerebral perfusion.

The surgical procedure (Video 1) is performed through a median sternotomy, which facilitates additional cardiac surgery if required. CPB is implemented from both venae cavae to the ascending aortic cannulation, with only the superior vena cava being snared, and rapid cooling is initiated. When the rectal temperature has been decreased to $30^{\circ} \mathrm{C}$, the ascending aorta is clamped, and a cold, crystalloid cardioplegic solution is administered through the aortic root cannula. Then circulatory arrest is induced at a rectal temperature of $28^{\circ} \mathrm{C}$ without any cerebral perfusion. The hemicircumference of the anterior surface of the arch between the left common carotid and left subclavian arteries is obliquely incised (Figure 1), and a J-Graft Open Stent (Japan Lifeline Co, Ltd, Tokyo, Japan; Figure 2) is inserted into the descending aorta with the preoperatively measured length, and the graft is subsequently deployed without any balloon dilation. The distal end of the stent graft is assessed with transesophageal echocardiography to confirm that the aneurysm is fully covered by the device. The proximal side of the graft is trimmed, and the posterior aortic wall and graft are continuously anastomosed under a table position of approximately $30^{\circ}$ degrees toward the main surgeon. Subsequently, the table position is turned approximately $30^{\circ}$ toward the assistant's side, and the graft is continuously sutured around the orifice of the left subclavian artery (Figure 3). The aortic incision and anterior side of the graft are continuously closed with the same suture. During circulatory arrest, circulating blood in the CPB circuit is warmed with a heat exchanger set to the maximum level around $35^{\circ} \mathrm{C}$ and the patient's body, except for the head, is warmed with a hyperthermiahypothermia system (Medi-Term II; Gaymar Inc, Orchard Park, NY). Deairing is performed by retrograde blood perfusion through the superior vena cava cannula at the end of the aortic closure. As soon as the arch has been closed, the aortic crossclamp is released and rapid rewarming is initiated by the perfusion of heated blood. If the aneurysm includes the subclavian artery, it is possible to close the subclavian artery during circulatory arrest, and the stent graft is sutured between the common carotid and left subclavian arteries. Next, the left subclavian artery is reconstructed with another 8 -mm graft under aortic side clamping during rewarming.

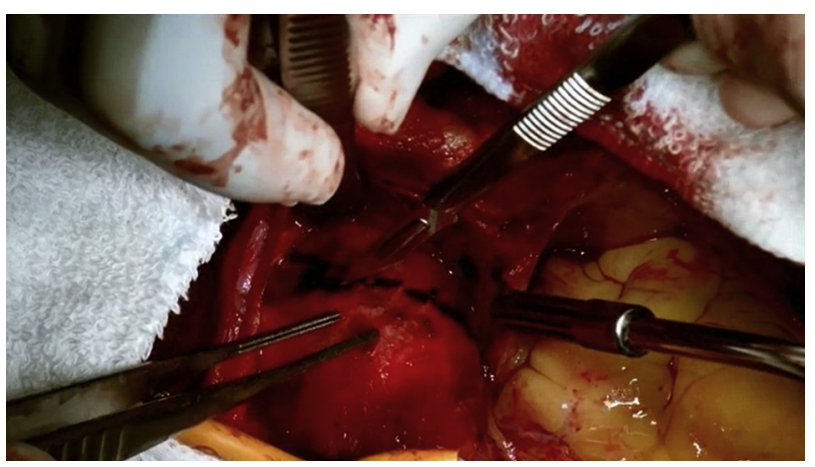

VIDEO 1. Distal limited open stenting procedure. Circulatory arrest is induced at a rectal temperature of $28^{\circ} \mathrm{C}$. The hemicircumference of the anterior surface of the arch between the left common carotid and left subclavian arteries is obliquely incised, and a J-Graft Open Stent (Japan Lifeline Co, Ltd, Tokyo, Japan) is inserted into the descending aorta with the preoperatively measured length. The proximal side of the graft is trimmed, and the posterior aortic wall and graft are continuously anastomosed under a table position of approximately $30^{\circ}$ toward the main surgeon. Subsequently, the table position is turned approximately $30^{\circ}$ toward the assistant's side, and the graft is continuously sutured around the orifice of the left subclavian artery. The aortic incision and anterior side of the graft are continuously closed with the same suture. Video available at: http://www.jtcvsonline.org/article/S0022-5223(16)31167-9/addons.

The mean follow-up duration was 31.1 months, ranging from 3 to 68 months. Follow-up information was obtained for all patients. At the time of this study, patients were assessed with the Mini-Mental State Examination (MMSE; Table 1). The MMSE includes 11 questions, and the best possible score is 30 points. Patients with an MMSE score of less than 20 points are considered to have dementia. ${ }^{3}$ The actuarial survival was calculated with the Kaplan-Meier method.

\section{RESULTS}

Coronary bypass grafting was concomitantly performed in 3 cases $(12.5 \%)$. The maze procedure and left atrial

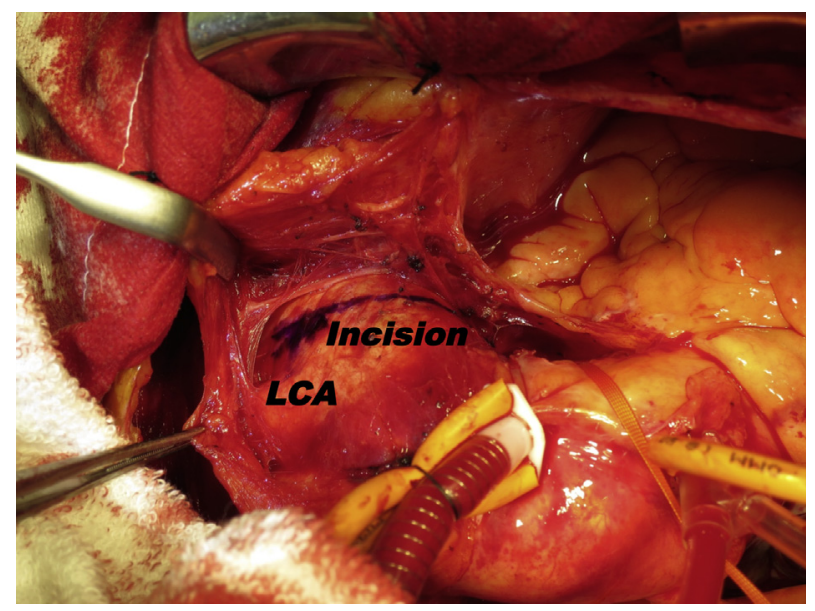

FIGURE 1. Aortic incision. The hemicircumference of the anterior surface of the arch between the left common carotid artery $(L C A)$ and the left subclavian artery is obliquely incised. 

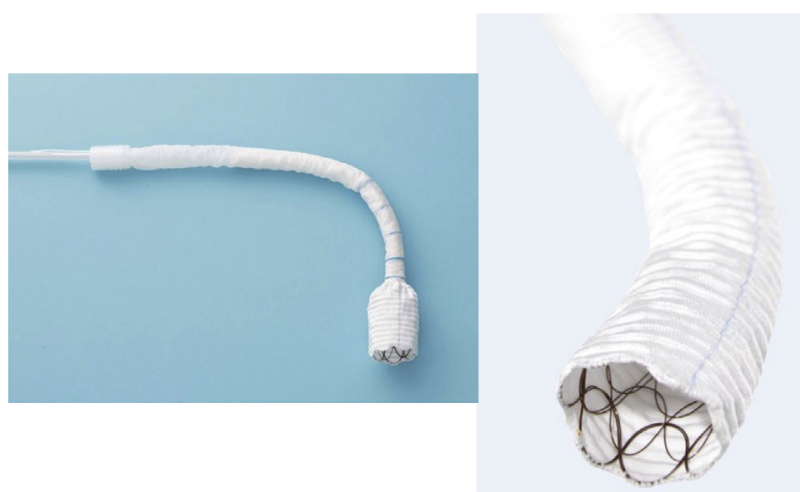

FIGURE 2. J-Graft Open Stent (Japan Lifeline Co, Ltd, Tokyo, Japan). A shape-memory alloy, which is made of nitinol wire with tip of $9 \mathrm{~cm}$ on the distal part, is attached to a woven structure graft.

appendage closure were performed in 1 case. One patient underwent reconstruction of the left subclavian artery. The average duration of circulatory arrest, aortic crossclamp, $\mathrm{CPB}$, and the overall operation were $17.0 \pm 3.3$ minutes, $27.8 \pm 11.6$ minutes, $106.1 \pm 14.1$ minutes, and $167.6 \pm 31.0$ minutes, respectively (Table 2). The durations of postoperative mechanical ventilation and the hospital stay were $6.4 \pm 3.8$ hours and $13.9 \pm 4.5$ days, respectively (Table 2). All patients woke up within 6 hours after the operation and were extubated without the incidence of delirium. There were no incidences of postoperative stroke, paraplegia, reexploration for bleeding, or acute renal failure. Postoperative 3-dimensional computed tomographic scans showed no end leakage in all patients (Figure 4). The in-hospital mortality was $0 \%$. During the follow-up period, 3 patients died, 1 each of heart failure, acute myocardial infarction, and gastric cancer.

At the time of this writing, 21 patients were well and visiting the outpatient clinic. Of those, 19 patients scored more than 20 points on the MMSE, indicating no development of dementia. The average score for the MMSE was $24.4 \pm 5.3$ points. No patients required the use of a wheelchair, and $17(81.0 \%)$ were visiting the clinic
TABLE 1. Mini-Mental State Examination

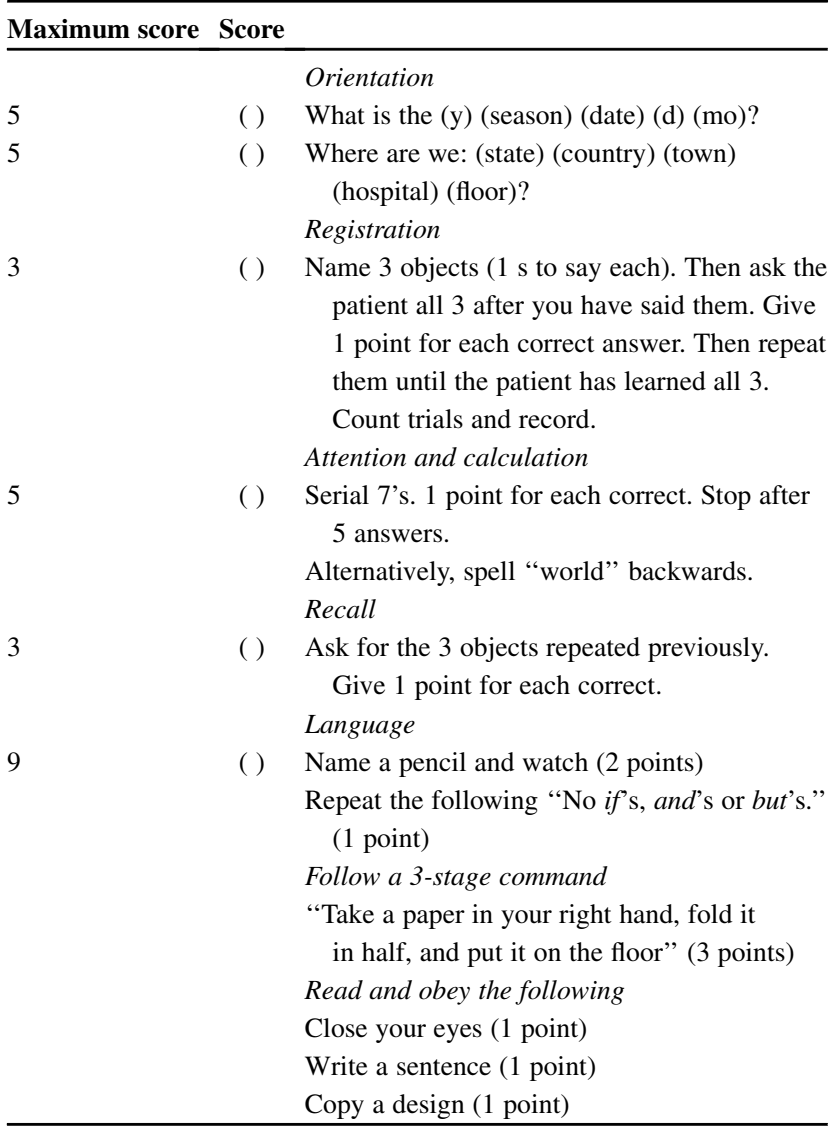

This questionnaire includes 11 questions, and the best possible score is 30 points. Patients with a Mini-Mental State Examination score of less than 20 points are considered to have dementia.

without family support. The actuarial survival at 5 years was $82.4 \%$ (Figure 5 ).

\section{DISCUSSION}

With the ever increasing human lifespan, cardiovascular surgeons are faced with treating an increasing number of elderly patients. Octogenarians often have concomitant
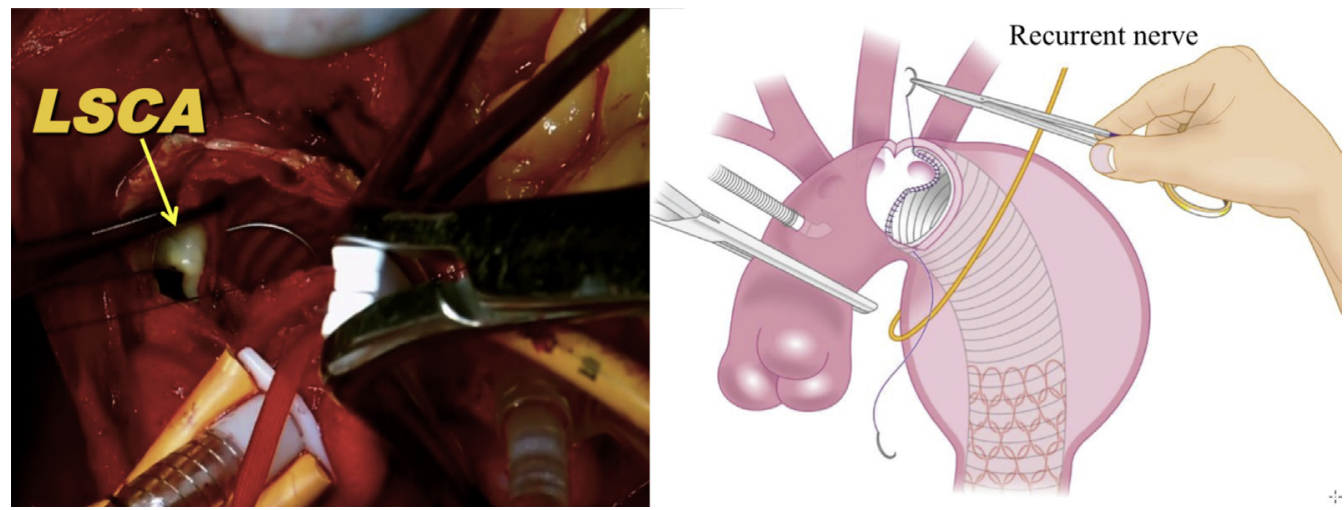

FIGURE 3. Photograph (left) and schema (right) of proximal anastomosis of the stent graft. The table position is turned approximately $30^{\circ}$ toward the assistant's side, and the graft is continuously sutured around the orifice of the left subclavian artery (LSCA). 
TABLE 2. Surgical results

\begin{tabular}{lc}
\hline Circulatory arrest (min) & $17.0 \pm 3.3$ \\
ACCT (min) & $27.8 \pm 11.6$ \\
CPB (min) & $106.1 \pm 14.1$ \\
OPT (min) & $167.6 \pm 31.0$ \\
Ventilation (h) & $6.4 \pm 3.8$ \\
HP stay (d) & $13.9 \pm 4.5$ \\
\hline Data are mean + SD $A C C T$. Aortic crossclamp time; $C P B$, cardiopulmonary bypass;
\end{tabular}

Data are mean \pm SD. $A C C T$, Aortic crossclamp time; $C P B$, cardiopulmonary bypass; $O P T$, operating time; $H P$, hospital stay.

diseases, such as renal insufficiency, chronic obstructive pulmonary disease, or degenerative cerebral disease. ${ }^{4}$ They thus may not be able to tolerate the prolonged surgical stress of deep hypothermia, a longer duration of cerebral exclusion, or CPB. Furthermore, a prolonged operation can increase mortality as a result of coagulopathy, cerebral ischemia, infection, or multiple organ failure. ${ }^{5}$ TEVAR is therefore an attractive option for treating thoracic aortic diseases in octogenarians. An incidence of approximately $8 \%$ of spinal and cerebral disorders during TEVAR has been reported, however, and this incidence is particularly high for elderly patients with mural thrombi and atherosclerotic plaques of the aortic wall. ${ }^{1}$

The distal limited open stenting procedure was developed to reduce the invasiveness of total arch replacement and to compensate for the disadvantages of TEVAR, such as the relatively high incidence of brain and spinal complications ${ }^{1}$ or type 1 endoleakage caused by markedly curved pathways

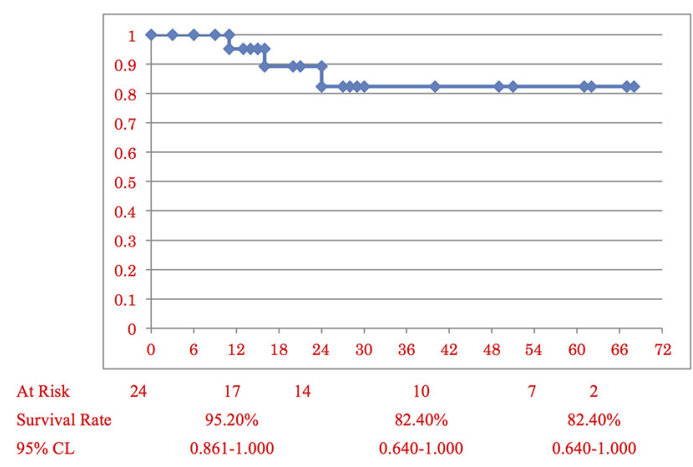

(Month)

FIGURE 5. Kaplan-Meier curve. The actuarial survival at 5 years was $82.4 \%$. $C L$, Confidence limits.

of the distal arch. $^{6}$ Various improvements have been made since open stenting was first reported by Kato and colleagues $^{7}$ and Sueda and associates ${ }^{8}$; however, deep hypothermia and selective cerebral perfusion, which are associated with an additional risk of cerebral embolization due to brain perfusion catheter insertion itself, are still required. Conversely, we do not use selective cerebral perfusion in our procedure, because the cerebral perfusion catheters are an obstacle to quick suture and it is possible to finish circulatory arrest within 20 minutes. No matter what unexpected situation arises, we can quickly start retrograde cerebral perfusion through the superior vena
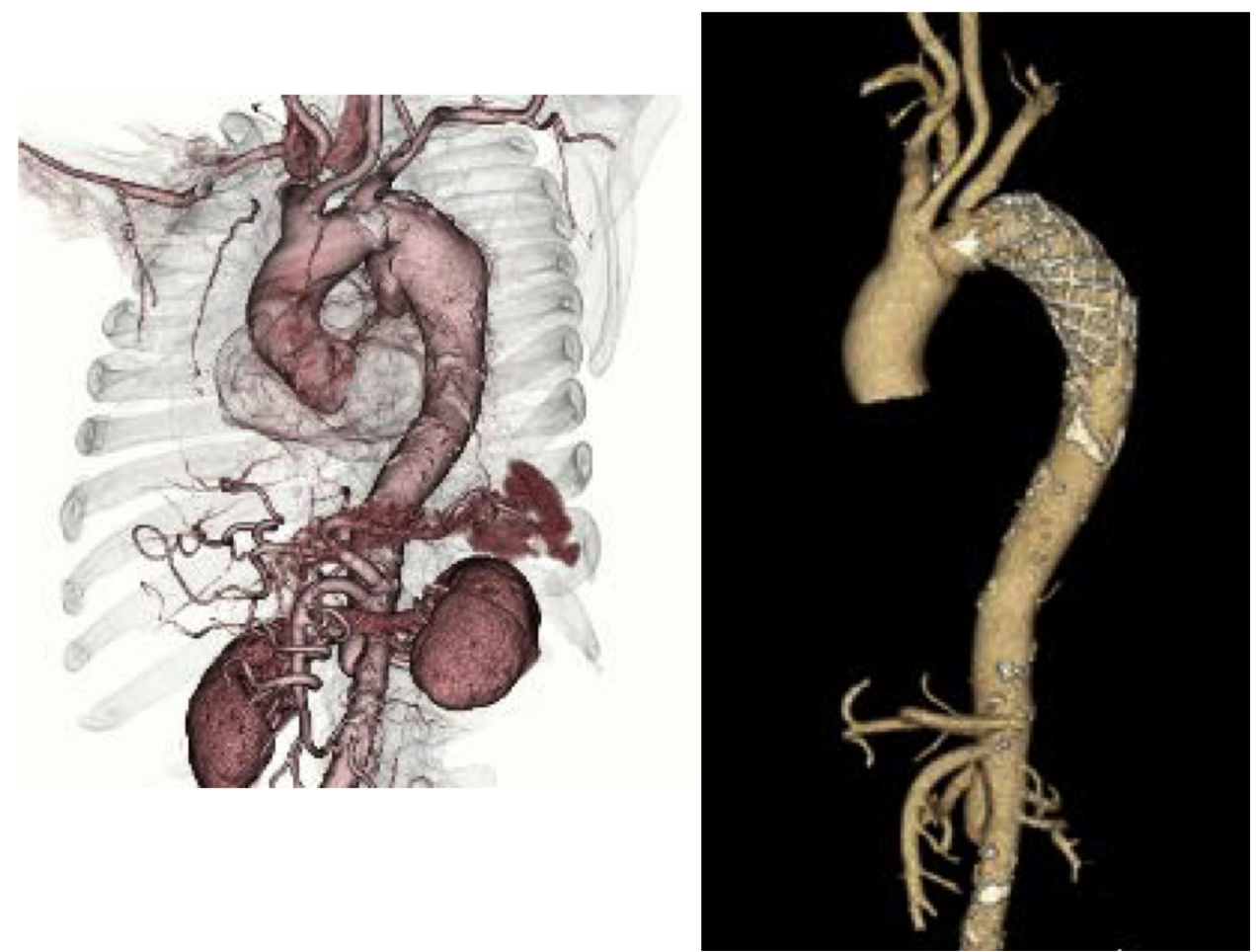

FIGURE 4. Preoperative (left) and postoperative (right) 3-dimensional computed tomographic scans. The preoperative 3-dimensional computed tomographic scan shows a large distal arch aneurysm. The postoperative 3-dimensional computed tomographic scan shows no end leakage. 
cava cannula. In the study reported here, however, unexpected retrograde cerebral perfusion was never required.

In this study, no incidence of brain complication was indicated, although the rectal temperature was approximately $28^{\circ} \mathrm{C}$ without any cerebral blood perfusion for brain protection. Cook and colleagues ${ }^{9}$ reported that deep hypothermia less than $22^{\circ} \mathrm{C}$ may not be necessary, and it may be associated with neurologic injury during selective cerebral perfusion. Greeley and coworkers ${ }^{10}$ mentioned that patients cooled to $28^{\circ} \mathrm{C}$ had a predicted brain ischemic tolerance of approximately 20 minutes. Our results suggest that moderate hypothermic arrest at $28^{\circ} \mathrm{C}$ without any cerebral blood perfusion within 20 minutes is safe. Another aspect of this procedure is rapid rewarming. It has been generally accepted that rewarming from deep hypothermia should be conducted as slowly as possible. ${ }^{11}$ In deep hypothermia, cerebral metabolism and oxygen extraction remain significantly reduced during rewarming and after $\mathrm{CPB}$, suggesting disordered cerebral metabolism and oxygen use after hypothermia. ${ }^{12}$ We therefore speculate that the potential mismatches in cerebral blood flow and metabolism after deep hypothermia are most likely expressed during rapid temperature or perfusion changes, such as during rewarming. Conversely, Greeley and colleagues $^{11}$ reported that patients cooled to $28^{\circ} \mathrm{C}$ demonstrated a return to baseline in cerebral blood flow during the rewarming phase and after weaning from CPB. We therefore believe that it is possible to induce rapid rewarming after moderate hypothermic circulatory arrest. Furthermore, it can shorten the durations of CPB and the overall operation. We believe that a shorter surgery can result in a better outcome, because it can minimize surgical stress related to deep hypothermia and a longer duration of CPB for weak octogenarians.

Distal limited open stenting provides a perfect early surgical outcome for octogenarians. All patients also received elective surgery for DAAA, so, we need to determine how many octogenarians have returned to their preoperative living status. Rapid demographic aging has important implications for health and social care. Cognitive disorders and dementia have a high individual impact, and they are strongly associated with age. ${ }^{13}$ A recent report estimated that the number of elderly people with dementia in the world will increase from 24 million to 82 million from 2000 to $2040 .{ }^{14}$ Our unique procedure can contribute to the survival of octogenarians. If patients have dementia or have become bedridden early during the follow-up, however, their family members may become very stressed because of the increased burden of having to care for the patients.

In this study, more than $80 \%$ of patients were actually visiting the clinic without family support; however, a cognitive assessment is a basic element for diagnosing dementia. The average score for the MMSE was $24.4 \pm 5.3$ points, and only 2 patients showed signs of dementia. We excluded patients who already had Alzheimer-type senile dementia from the study. It is evident that our unique distal limited open stenting for DAAA provides a good postoperative quality of life at a level close to preoperative living conditions, even in the case of octogenarians. The preoperative clinical status is the most significant factor for predicting early death, and in general, surgery should only be considered an effective treatment for patients with a good preoperative clinical status. In this study, although octogenarian patients did have some a preoperative comorbidities, such as coronary artery disease, respiratory disorder, atrial fibrillation, an old cerebral infarction, and shaggy aorta, their quality of life was still good after distal limited open stenting.

\section{CONCLUSIONS}

Distal limited open stenting is considered a safe and effective surgical treatment, especially in octogenarians with DAAA. This unique technique enables surgeons to avoid cerebral embolization, spinal disorder, and phrenic and recurrent nerve injury, and it shortens the durations of circulatory arrest and CPB for weak octogenarians.

\section{Conflict of Interest Statement}

Authors have nothing to disclose with regard to commercial support.

\section{References}

1. Buth J, Harris PL, Hobo R, van Eps R, Cuypers P, Duijm L, et al. Neurologic complications associated with endovascular repair of thoracic aortic pathology: Incidence and risk factors. A study from the European Collaborators on Stent/ Graft Techniques for Aortic Aneurysm Repair (EUROSTAR) registry. J Vasc Surg. 2007;46:1103-10; discussion 1110-1.

2. Hata M, Akiyama K, Orime Y, Wakui S, Nakamura T, Shiono M. Less invasive quick open stenting using a J graft open stent. Thorac Cardiovasc Surg. 2016;64:330-2.

3. Folstein MF, Folstein SE, McHugh PR. "Mini-mental state." A practical method for grading the cognitive state of patients for the clinician. J Psychiatr Res. 1975; 12:189-98.

4. Ehrlich M, Fang WC, Grabenwöger M, Cartes-Zumelzu F, Wolner E, Havel M. Perioperative risk factors for mortality in patients with acute type A aortic dissection. Circulation. 1998;98(Suppl II):II294-8.

5. Chiappini B, Camurri N, Loforte A, Marco L, Bartolomeo R, Marinelli G. Outcome after aortic valve replacement in octogenarians. Ann Thorac Surg. 2004;78:85-9.

6. Gorlitzer M, Weiss G, Thalmann M, Mertikian G, Wislocki W, Meinhart J, et al. Combined surgical and endovascular repair of complex aortic pathologies with a new hybrid prosthesis. Ann Thorac Surg. 2007;84:1971-7.

7. Kato M, Ohnishi K, Kaneko M, Ueda T, Kishi D, Mizushima T, et al. New graft-implanting method for thoracic aortic aneurysm or dissection with a stented graft. Circulation. 1996;94(Suppl II):II188-93.

8. Sueda T, Watari M, Okada K, Orihashi K, Matsuura Y. Endovascular stent-grafting through the aortic arch: An alternative approach for distal arch aortic aneurysm. Ann Thorac Surg. 2000;70:1251-4.

9. Cook RC, Gao M, Macnab AJ, Fedoruk LM, Day N, Janusz MT. Aortic arch reconstruction: safety of moderate hypothermia and antegrade cerebral perfusion during systemic circulatory arrest. J Cardiovasc Surg. 2006;21:158-64.

10. Greeley WJ, Kern FH, Ungerleider RM, Boyd JL III, Quill T, Smith LR, et al. The effect of hypothermic cardiopulmonary bypass and total circulatory arrest on cerebral metabolism in neonates, infants, and children. J Thorac Cardiovasc Surg. 1991;101:783-94. 
11. Rosner MJ, Rosner SD, Johnson AH. Cerebral perfusion pressure: management protocol and clinical results. J Neurosurg. 1995;83:949-62.

12. Croughwell ND, Frasco P, Blumenthal JA, Leone BJ, White WD, Reves JG. Warming during cardiopulmonary bypass is associated with jugular bulb desaturation. Ann Thorac Surgery. 1992;53:827-32.

13. Prince M. Dementia in developing countries. A consensus statement from the 10/66 Dementia Research Group. Int J Geriatr Psychiatry. 2000;15:14-20.
14. Ferri CP, Prince M, Brayne C, Brodaty H, Fratiglioni L, Ganguli M, et al Global prevalence of dementia: a Delphi consensus study. Lancet. 2005;366: 2112-7.

Key Words: aortic surgery, distal aortic arch aneurysm, open stent implantation

Readers who found these articles interesting may also like to read the following papers found in recent and future issues of our sister publications, Seminars in Thoracic and Cardiovascular Surgery and Operative Techniques in Thoracic and Cardiovascular Surgery!

\section{Acquired: Aortic Disease}

Original Submission: Outcomes of Open Surgical Repair for Type B Dissecting Aortic Aneurysm with Alternative Methods in the Endovascular Stent Era. Mitsumasa Hata. Semin Thorac Cardiovasc Surg 2015; Summer; 27(2):106-112.

Editorial Commentary: It is Difficult to Compare Apples and Oranges: Acute and Chronic Type B Aortic Dissections, Complicated and Uncomplicated, are Different and Should be Treated as Such. Ourania Preventza. Semin Thorac Cardiovasc Surg 2015; Summer; 27(2):113-114.

News and Views: Treatment of Thoracic Aortic Aneurysm: Role of Earlier Intervention. Bulat A. Ziganshin. Semin Thorac Cardiovasc Surg 2015; Summer; 27(2);135-143.

Aortic root enlargement during aortic valve replacement: Nicks and Manouguian techniques. Kendra J Grub. Oper Tech Thorac Cardiovasc Surg 2015; Autumn; 20(3):206-218.

The Konno-Rastan procedure for anterior aortic annular enlargement. Mark E. Roeser. Oper Tech Thorac Cardiovasc Surg 2015: Autumn; 20(3):219-233. 